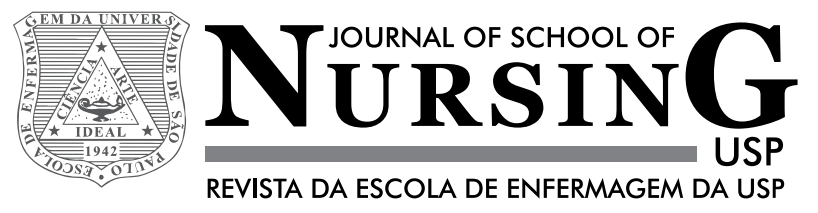

\title{
Skin tear prevalence and associated factors: a systematic review
}

\author{
Prevalência de lesão por fricção e fatores associados: revisão sistemática \\ Prevalencia de lesión por fricción y factores asociados: revisión sistemática
}

Kelly Cristina Strazzieri-Pulido ${ }^{1}$, Giovana Ribau Picolo Peres ${ }^{1}$, Ticiane Carolina Gonçalves Faustino Campanili', Vera Lúcia Conceição de Gouveia Santos ${ }^{2}$

${ }^{1}$ Universidade de São Paulo, Escola de Enfermagem, Programa de Pós-Graduação em Enfermagem na Saúde do Adulto, São Paulo, SP, Brazil.

${ }^{2}$ Universidade de São Paulo, Escola de Enfermagem, Departamento de Enfermagem Médico-Cirúrgica, São Paulo, SP, Brazil.

\begin{abstract}
Objective: To identify and analyse skin tear prevalence and factors associated with its occurrence. Method: Systematic review of literature of studies published until June 2014 including studies published in full in English, Spanish or Portuguese. The studies were analysed according to the Strengthening the Reporting of Observational Studies in Epidemiology and the Guidelines for Critically Appraising Studies of Prevalence or Incidence of a Health Problem. Results: The analysis of eight studies showed skin tear prevalence of $3.3 \%$ to $22 \%$ in the hospital setting and $5.5 \%$ to $19.5 \%$ in homecare. Advanced age, dependence on basic activities of daily life, frail elderly, level of mobility, agitated behavior, non-responsiveness, greater risk for concurrent development of pressure ulcers, cognitive impairment, spasticity and photoaging were cited as risk factors. Conclusion: Skin tear prevalence ranged from $3.3 \%$ to $22 \%$ and is mainly associated with advanced age and dependence on basic activities of daily life.
\end{abstract}

\section{DESCRIPTORS}

Wounds and Injuries; Prevalence; Cross-Sectional Studies; Epidemiology; Review. 


\section{INTRODUCTION}

Caring for people with fragile skin is a challenge when a minor trauma can result in Skin Tear (ST) ${ }^{(1-3)}$.

Although some researchers suggest that Skin Tear is more prevalent than pressure ulcers and burns ${ }^{(4-5)}$, ST go unnoticed as they are shallow traumatic wounds, occurring mainly in elderly ends resulting from friction or a combination of friction and shear, leading to separation of the epidermis from the dermis (partial thickness wound) or completely separating the epidermis and the dermis from the underlying structures (total thickness wound) ${ }^{(6)}$. They are regarded as inherent to the age, inducing the feeling of an irrelevant condition, however, they cause pain and can easily be infected ${ }^{(2-4,7)}$.

Because they are relegated as mere casual unavoidable incidents, there is little interest and therefore, they are underdiagnosed. The lack of diagnostic accuracy and understanding of the causes involved, contributes to increasing pain and suffering, healing time and treatment costs, negatively affecting the quality of care ${ }^{(2-4,7-8)}$.

For less than 25 years, researchers have slowly begun to monitor the epidemiology of ST in order to build and refine appropriate nomenclature and risk assessment instruments and classification ${ }^{(8-9)}$, fundamental instruments for the evaluation of the wound and planning care actions, which are essential for its prevention ${ }^{(10-11)}$.

Simple measures such as the identification of patients at risk and the implementation of prevention protocols are proving to be effective to prevent ST or minimize its severity $^{(12)}$. Researches ${ }^{(1,13)}$ show that the occurrence of ST decreases as soon as an individual is identified at risk and preventive measures are implemented.

In order to bring tangible foundations on all scientific knowledge that still needs to be built on the ST, the International Skin Tear Advisory Panel ${ }^{(3)}$ recommends and encourages the development of studies to elucidate the epidemiology of ST in the health services and in the community.

This review aimed at identifying and analyzing the information available in the literature on the prevalence of ST, as well as factors associated with its occurrence in children, adults and elderly.

\section{METHOD}

Systematic review of the literature according to the recommendations of the Cochrane Collaboration ${ }^{(14)}$.

The guiding question of this review was: What is the information available in the literature on the prevalence and factors associated with ST in children, adults and elderly? To clarify it, the following electronic databases were consulted: CINAHL, Cochrane, EBM Reviews, Embase, LILACS, PubMed, SciELO, Scopus and Web of Science up to June 2014. For the selection of studies, we used the following criteria: to be published in English, Spanish or Portuguese until June 2014, to be available in full and to be an epidemiological research, that is, directed at the investigation of the prevalence of ST. Book chapters, conference abstracts, review articles, case reports, consensus, editorials, guidelines, correspondences, clinical trials, cohort studies and casecontrol studies were excluded.

The search strategy was based not only on indexed descriptors by Medical Subject Headings Section and Descriptors in Health Sciences - bold in Box 1 - but also on keywords used in narrative reviews and up to date studies, since the terminology about ST is not uniform. The search for studies was performed using Boolean operators AND and OR, respecting the peculiarities of each database searched. Chart 1 shows the search strategy.

Chart 1 - Search strategy - Sao Paulo, 2014.

\begin{tabular}{|c|l|}
\hline Number & Descritor MeSH/ DeCS or key-word \\
\hline$\# \mathbf{1}$ & Older people \\
\hline$\# \mathbf{2}$ & Adult \\
\hline$\# \mathbf{3}$ & Child \\
\hline$\# \mathbf{4}$ & Skin aging OR Elderly skin \\
\hline$\# \mathbf{5}$ & Prevalence OR Epidemiology \\
\hline$\# \mathbf{6}$ & $\begin{array}{l}\text { Lacerations OR Mangled wounds OR Tear wounds } \\
\text { OR Rag wounds OR Skin lacerations OR Traumatic } \\
\text { laceration OR Pretibial laceration OR Skin tears OR } \\
\text { Skin trauma OR Skin stripping }\end{array}$ \\
\hline$\# \mathbf{7}$ & (\#1 OR \#2 OR \#3 OR \#4) AND (\#5) AND (\#6) \\
\hline &
\end{tabular}

The search for studies was conducted by one of the authors in each of the electronic databases. The search results were exported to EndNote Web ${ }^{\circledR}$ program, which stored the following data from each study: title, authors, journal title, number, volume, page, section, abstract and keywords.

The initial selection of studies was performed from the title and abstract analysis. The studies were randomized among the authors, and each of them had to be analyzed by two authors. Studies, which generated doubts about the relevance of their inclusion, were analyzed by a third author.

Studies that had their abstracts selected were redeemed in full and randomly distributed among the authors, and each one of them had to be analyzed by two authors. A third author judged the validation of analysis, evaluating and comparing $30 \%$ of the studies, chosen through a raffle.

The studies were analyzed descriptively and the results were grouped and presented with respect to: year of publication, country where the study was conducted, methods (population/sample; prevalence of ST; ST instruments used for classification, and statistics strategies analysis) and the main results found by the authors (prevalence of ST and factors associated with ST, when identified).

To assess the quality of the studies included in this review both the Strengthening the Reporting of Observational Studies in Epidemiology (STROBE) ${ }^{(15)}$ and the Guidelines for Critically Appraising Studies of Prevalence or Incidence of a Health Problem ${ }^{(16)}$ were used.

STROBE, translated into Portuguese by Malta et al. ${ }^{(15)}$, contains 22 items with recommendations on what should be included in a more accurate and full description of observational studies. Each of the 22 criteria received a score of 0 
to 1 . The total score was converted into percentage to better assess the quality of the studies. The items that reached a percentage higher than $50 \%$ were considered of good quality.

The Guidelines for Critically Appraising Studies of Prevalence or Incidence of a Health Problem, developed by Loney et al. ${ }^{(16)}$ consist of eight questions on the adequacy and accuracy of the study relating to the validity of the methods, interpretation and applicability of the results. Each item was rated with a point, generating maximum score of 8 points. Loney et al. ${ }^{(16)}$ did not establish quality categories neither for the score obtained nor for the cut-off score. Studies which reached more than 4 points were considered of good quality. The system is presented in Chart 2.

Chart 2 - Guidelines for Critically Appraising Studies of Prevalence or Incidence of a Health Problem - Sao Paulo, 2014.

\begin{tabular}{|c|c|}
\hline \multicolumn{2}{|c|}{$\begin{array}{l}\text { Guidelines for Critically Appraising Studies of Prevalence or } \\
\text { Incidence of a Health Problem }\end{array}$} \\
\hline Item & Score \\
\hline 1. Random sample or whole population & 1 point \\
\hline 2. Unbiased sampling frame & 1 point \\
\hline 3. Adequate sample size & 1 point \\
\hline 4. Measures were the standard & 1 point \\
\hline 5. Outcomes measured by unbiased assessors & 1 point \\
\hline 6. Adequate response rate, refusers described & 1 point \\
\hline 7. Confidence intervals, subgroup analysis & 1 point \\
\hline 8. Study subjects described & 1 point \\
\hline Maximum score & 8 points \\
\hline
\end{tabular}

Source: Loney PL, Chambers LW, Bennett KJ, Roberts JG, Stratford PW. Critical appraisal of the health research literature: prevalence or incidence of a health problem. Chronic Dis Can. 1998;19(4):170-6.(16)

\section{RESULTS}

The search in the nine databases resulted in 8,095 studies. After removing 2,426 duplicates, 5,669 studies were directed to title screening. After reading the titles, 5,433 studies were removed, leaving 236 studies for abstract analysis. Of these, book chapters, conference abstracts, review studies, case reports, consensus, editorials, guidelines, correspondences, clinical trials, cohort studies and casecontrol were excluded. Remaining only nine studies on the prevalence of ST, of which eight ${ }^{(17-24)}$ met the inclusion criteria and were read in full. The only excluded study ${ }^{(25)}$ did not meet the language criterion, since it was published in Chinese.

Embase (57.42\%) and PubMed (34.48\%) were the databases that found the largest number of studies. The less representative databases were Cochrane (0.84\%), CINAHL (0.21\%), SciELO (0.10\%), EBM Reviews (0.09\%) and LILACS (0.01\%), as shown Table 1.

Chart 3 presents a summary of the six selected articles.

Table 1 - Studies identified according to databases - Sao Paulo, 2014.

\begin{tabular}{lcc}
\hline \multirow{2}{*}{ Databases } & \multicolumn{2}{c}{ Identified studies } \\
\cline { 2 - 3 } & $\mathbf{N}$ & $\%$ \\
\hline CINAHL & 17 & 0.21 \\
Cochrane & 68 & 0.84 \\
EBM Reviews & 07 & 0.09 \\
Embase & 4644 & 57.42 \\
LILACS & 01 & 0,01 \\
PubMed & 2788 & 34,48 \\
SciELO & 08 & 0,10 \\
Scopus & 283 & 3.50 \\
Web of Science & 279 & 3.45 \\
\hline Total & 8087 & 100 \\
\hline
\end{tabular}

Chart 3 - Study stratified by author, year of publication, country, methods, results and quality score - Sao Paulo, 2014.

\begin{tabular}{|l|l|l|l|l|l|}
\hline Author/Year of publication & Country & Methods & Results (prevalence of ST) & STROBE & LONEY \\
\hline $\begin{array}{l}\text { Carville K e Lewin G, } \\
1998^{(17)}\end{array}$ & Australia & $\begin{array}{l}\text { Retrospective study } \\
\text { n=1,146 patients in homecare. Auditing } \\
\text { charts. It does not cite instrument for ST clas- } \\
\text { sification. It does not cite statistical methods }\end{array}$ & $\begin{array}{l}5,5 \% \\
\text { (excluding ST of lower } \\
\text { limbs) } \\
\text { (It does not have Cl) Ad- } \\
\text { vanced age }\end{array}$ & $48 \%$ & 4.0 \\
\hline $\begin{array}{l}\text { Carville K e Smith JA, } \\
2004^{(18)}\end{array}$ & Australia & $\begin{array}{l}\text { Cross-sectional study } \\
\text { n=492 war veterans in homecare } \\
\text { Physical examination } \\
\text { It does not cite instrument for } \\
\text { Skin tear classification } \\
\text { Cox regression analysis }\end{array}$ & $\begin{array}{l}19.5 \% \\
\text { (It does not have Cl) } \\
\text { Advanced age } \\
\text { Frail elderly }\end{array}$ & $61 \%$ & 6.0 \\
\hline $\begin{array}{l}\text { McErlean B, Sandison S, } \\
\text { Muir D, Hutchinson B e } \\
\text { Humphreys W, 2004 }\end{array}$ & Australia & $\begin{array}{l}\text { Cross-sectional study } \\
\text { n=187 patients admitted to } \\
\text { a tertiary hospital } \\
\text { Physical examination } \\
\text { Payne-Martin Classification } \\
\text { System for Skin Tears } \\
\text { It does not cite statistical methods }\end{array}$ & $\begin{array}{l}11 \% \\
\text { (It does not have CI) } \\
\text { Level of dependency and } \\
\text { mobility }\end{array}$ & $68 \%$ & 6.5 \\
\hline
\end{tabular}




\begin{tabular}{|c|c|c|c|c|c|}
\hline Author/Year of publication & Country & Methods & Results (prevalence of ST) & STROBE & LONEY \\
\hline $\begin{array}{l}\text { McLane KM, Bookout K, } \\
\text { McCord S, McCain J e Jef- } \\
\text { ferson LS, 2004 }\end{array}$ & $\begin{array}{l}\text { United } \\
\text { States of } \\
\text { America }\end{array}$ & $\begin{array}{l}\text { Cross-sectional study } \\
\mathrm{n}=1,064 \text { patients in children's hospitals (up } \\
\text { to } 17 \text { years) Physical examination } \\
\text { It does not cite instrument for } \\
\text { ST classification } \\
\text { It does not cite statistical methods }\end{array}$ & $\begin{array}{l}17 \% \\
\text { (It does not have } \mathrm{Cl} \text { ) } \\
\text { It does not refer to associ- } \\
\text { ated factors }\end{array}$ & $58 \%$ & 4.5 \\
\hline $\begin{array}{l}\text { Santamaria N, Carville K e } \\
\text { Prentice J, 2009 }\end{array}$ & Australia & $\begin{array}{l}\text { Cross-sectional study } \\
\mathrm{n}=5,800 \text { admitted patients in public health } \\
\text { institutions } \\
\text { Physical examination } \\
\text { It does not cite instrument } \\
\text { for ST } \\
\text { Confidence intervals for wounds in general, } \\
z \text {-score and } p \text { value }\end{array}$ & $\begin{array}{l}8 \% \\
\text { (It does not have Cl) Ad- } \\
\text { vanced age }\end{array}$ & $58 \%$ & 5.0 \\
\hline $\begin{array}{l}\text { Amaral AFS, Strazzieri- } \\
\text { Pulido KC e Santos VLG, } \\
2012^{(22)}\end{array}$ & Brazil & $\begin{array}{l}\text { Cross-sectional study } \\
\mathrm{n}=157 \text { admitted patients with cancer } \\
\text { Physical examination } \\
\text { STAR Skin Tear Classification System } \\
\text { Chi-square test and } \mathrm{p} \text { value }\end{array}$ & $\begin{array}{l}3.3 \% \\
\text { (It does not have Cl) } \\
\text { Less independence and } \\
\text { autonomy } \\
\text { for self-care } \\
\text { Agitated behavior or } \\
\text { Non-responsiveness; } \\
\text { Higher risk for concurrent } \\
\text { development of pressure } \\
\text { ulcers }\end{array}$ & $87 \%$ & 7.5 \\
\hline $\begin{array}{l}\text { LeBlanc K, Christensen D, } \\
\text { Cook J, Culhane B e Gutier- } \\
\text { rez O, 2013 }\end{array}$ & Canada & $\begin{array}{l}\text { Cross-sectional study } \\
\mathrm{n}=113 \text { patients in long-stay institutions } \\
\text { Physical examination } \\
\text { Payne-Martin Classification } \\
\text { System for Skin Tears } \\
\text { t-student, Chi-square, adherence and Bonfer- } \\
\text { roni tests }\end{array}$ & $\begin{array}{l}22 \% \\
\text { (It does not have } \mathrm{Cl} \text { ) } \\
\text { Dependence for basic } \\
\text { activities of daily life } \\
\text { Cognitive impairment } \\
\text { Spasticity }\end{array}$ & $90 \%$ & 6.5 \\
\hline $\begin{array}{l}\text { Koyano Y, Nakagami G, } \\
\text { lizaka S, Minematsu T, } \\
\text { Noguchi H, Tamai N, et al., } \\
2014^{(24)}\end{array}$ & Japan & $\begin{array}{l}\text { Cross-sectional study } \\
\mathrm{n}=410 \text { patients admitted to retirement geriat- } \\
\text { ric hospital } \\
\text { Physical examination } \\
\text { STAR Skin Tear Classification System } \\
\text { Calculation of prevalence }\end{array}$ & $\begin{array}{l}3.9 \% \\
\text { (It does not have } \mathrm{Cl}) \\
\text { photoaging }\end{array}$ & $87 \%$ & 7.0 \\
\hline
\end{tabular}

The studies are mostly from Australia (4) ${ }^{(17-19,21)}$, predominantly from hospital settings $(6)^{(19-24)}$ or homecare (2) ${ }^{(17,18)}$. Physical examination was the main strategy for data collection, being held in seven studies ${ }^{(18-24)}$. Payne-Martin Classification System for Skin Tears was used by one of the Australian ${ }^{(19)}$ and the Canadian ${ }^{(23)}$ studies. The Brazilian study ${ }^{(22)}$, as well as Japanese ${ }^{(24)}$, used the Classification System STAR - Skin tears STAR Skin Tear Classification System. However, most studies $(4)^{(17-18,20-21)}$ did not mention which instrument was used for the classification of ST.

The prevalence of ST ranged from $3.3 \%$ to $22 \%$ in the hospital setting ${ }^{(19-24)}$ and $5.5 \%$ to $19.5 \%$ in homecare ${ }^{(17-18)}$. With regard to risk factors associated with ST, advanced age (3) $)^{(17-18,21)}$ and dependence for basic activities of daily life $(3)^{(19,22-23)}$ were the most cited. Other factors mentioned were frail elderly ${ }^{(18)}$, level of mobility, agitated behavior, nonresponsiveness, greater risk for concurrent development of pressure ulcers $^{(22)}$, cognitive impairment, spasticity ${ }^{(23)}$ and photoaging ${ }^{(24)}$. One study ${ }^{(20)}$ did not mention risk factors associated with ST.

Only one study ${ }^{(17)}$ was not considered of good quality, reaching $48 \%$ of STROBE and 4 points in the system developed by Loney et al. ${ }^{(16)}$. However, the performance of all studies $^{(17-24)}$ was hampered, since none of them had confidence intervals on the estimates of prevalence, and most (4) ${ }^{(17,19-21)}$ did not describe the study subjects.

\section{DISCUSSION}

In the hospital setting, the ST prevalence ranged from $3,3 \%^{(22)}$ to $22 \%{ }^{(23)}$. The lowest rates $(3.3 \%, 3.9 \%$ and $8 \%)$ were identified, respectively, in the studies developed in Brazil $^{(22)}$, in Japan ${ }^{(24)}$ and in Australia ${ }^{(21)}$. The Brazilian study ${ }^{(22)}$ identified the prevalence of ST in adult patients hospitalized with cancer, the Japanese study ${ }^{(24)}$ in a geriatric retired hospital and the Australian study ${ }^{(21)}$ quantified the epidemiology of wounds, including ST, in all patients, regardless of age, admitted to hospitals/linked to the public health system hospitals of Western Australia.

Studies conducted in Australia ${ }^{(19)}$, in the United States of America ${ }^{(20)}$ and in Canada ${ }^{(23)}$ identified the highest prevalence of ST (11\%, 17\% and 22\%). The Australian study ${ }^{(19)}$ identified ST prevalence in adult patients admitted to a tertiary hospital, the American study ${ }^{(20)}$ documented the prevalence of pressure ulcers and other wounds, including ST, in hospitalized children, and the Canadian study ${ }^{(23)}$ identified it on patients admitted to a long-term care facility.

Regarding homecare, all studies were conducted in Western Australia and the ST prevalence ranged from $5.5 \%{ }^{(17)}$ to $19.5 \%{ }^{(18)}$. The lowest prevalence $(5.5 \%)$ was identified in the study in patients with wounds being cared at home ${ }^{(17)}$. At that time, the authors chose to exclude ST in lower limbs. In a later study ${ }^{(18)}$, conducted with patients 
from the Department of Veterans' Affairs in homecare for wound, the authors found a significantly higher prevalence (19.5\%). When lower limb ST were included, there was a $10 \%$ increase in the prevalence of this type of wound ${ }^{(18)}$.

As for the factors associated with ST, advanced age was identified in three studies analyzed ${ }^{(17-18,21)}$, and frail elderly in one study ${ }^{(18)}$. Physiological changes associated with aging expose the elderly population to ST more than any other risk group. There is consensus among experts that it happens for two reasons: the weakening of the skin and susceptibility to trauma ${ }^{(3-4,7-8,11,13,26-27)}$.

In the first case, with skin aging, or intrinsic aging, that is, premature increase in the keratinization of the epidermis and enlargement and flattening of skin grooves, along with the loss of the folding of the basal lamina. Consequently, the anchoring system between the layers of epidermis and dermis do not withstand well as to friction and shear ${ }^{(27)}$.

On the other hand, in the dermis, fibroblasts begin to produce less collagen type I and more type III. Collagen fibers become tenuous, fragmented and separated by large areas occupied by fundamental amorphous substance. The mucopolysaccharides lose its structural function and is present as an amorphous pellet. The skin loses tensile strength, toughness, elasticity and extensibility ${ }^{(27)}$.

The production of sweat and sebaceous glands is also reduced with age, skin becomes dehydrated, dry and inelastic. The subcutaneous layer becomes thinner and the fat pad less efficient in absorbing impact. The skin thickness decreases progressively, reaching a $20 \%$ loss in thickness ${ }^{(27)}$.

The findings obtained in another study ${ }^{(24)}$, infer that the risk factors for ST are not related only to the effects of skin aging but also to photoaging, or extrinsic aging. In the epidermis, exposure to ultraviolet radiation leads to thinning of the spinous layer and the flattening of the dermalepidermal junction, while the dermis, is related to decreased collagen synthesis, as well as the increase of its degradation ${ }^{(28)}$. Photoaging, therefore, when enhancing skin aging, contribute further to their fragility, increasing thereby the risk for $\mathrm{ST}^{(24)}$.

Added to the fragile skin of the elderly, they also present susceptibility to trauma. That happens because, over the years, the increase of musculoskeletal stiffness and muscle spasticity reduce sensory sensitivity, visual acuity and cognitive ability, leading to loss of physical mobility and increasing dependence for basic activities of daily life. All of these changes contribute to the considerable increase in the risk for trauma and make advanced age a major risk factor for $\mathrm{ST}^{(3-4,7-8,11,13,26-27)}$.

Dependence for basic activities of daily living ${ }^{(19,22-23)}$, non-responsiveness (which incurs total dependence), levels of mobility ${ }^{(22)}$ and spasticity ${ }^{(23)}$ were also identified as risk factors associated with ST.

In a study conducted with fully dependent elderly, who required assistance for basic activities of daily life, had large number of ST, particularly in the upper limbs ${ }^{(11)}$. They occurred during routine care, such as dressing and bathing, and during placements and transfers. Almost half of the ST (48\%) occurred in bedridden elderly and $11 \%$ in those who required assistance to walk. In a descriptive study during six months of observation, it was found that the chances of presenting ST increased in the presence of gait difficulties $^{(7)}$. Wheelchairs were also associated with $25 \%$ of occurred traumas ${ }^{(9)}$.

Agitated behavior also figured as a risk factor associated with the occurrence of $\mathrm{ST}^{(22)}$. Researchers ${ }^{(11)}$ considered it as a predisposing factor to trauma and therefore, ST, and included psychomotor agitation as one of the risk items being investigated for their risk ST assessment instrument, the Skin Integrity Risk Assessment Tool.

The decline in cognitive ability stems from the physiological processes of normal aging or a transitional stage for dementias, reflecting in other cognitive domains beyond memory and interfering with work capacity and social life ${ }^{(3)}$. Some authors ${ }^{(7,23)}$ found in their studies that the chances of presenting ST increased in the presence of cognitive impairment.

Newborns and children are also susceptible to ST and constitute the second largest risk group. The authors of the study confirmed that ST prevalence (17\%) is higher than the pressure ulcer $(4 \%)$ in the pediatric population ${ }^{(20)}$. The age group up to 3 months old showed to be the most susceptible, because, besides having poor stratum corneum and dermal-epidermal junction undeveloped at birth, the dermis is thin, with only $60 \%$ of the thickness when compared to adult dermis. Tapes and adhesive bandages are identified as the main responsible for ST in this age group ${ }^{(20,29)}$.

Clinical experience, however, provides strong evidence that $\mathrm{ST}$ is not restricted to the extremes of age $\mathrm{e}^{(4,29-30)}$. Although elderly and newborns constitute the largest risk groups for ST, there are other groups which are prone to embrittlement of the skin and should not be ignored, such as critically ill individuals (in intensive care, or who have suffered major trauma or large surgery) at the end of life, or suffering from multiple extrinsic and intrinsic risk factors for ST regardless of age ${ }^{(29-30)}$.

While studying patients hospitalized with cancer, the authors found many individuals under 50 years old with $\mathrm{ST}^{(22)}$. The skin, like any other organ, can also fail. A severe medical condition certainly compromise the body's homeostatic mechanisms, which can cause skin to divert blood to vital organs, resulting in decreased skin and soft tissue perfusion and, consequently, compromising the metabolic processes of the skin. Small traumas would be able to cause major complications such as bleeding, gangrene, infection, pressure ulcers and ST. The tolerance to pressure and friction decreases in such a way that these conditions can make it impossible to prevent the breakage of the skin integrity ${ }^{(30)}$.

Hospitalized patients with cancer and ST also had a higher risk for pressure ulcer development (60\%) than those without ST $(12.5 \%)^{(22)}$. Similarly to this study ${ }^{(22)}$ other authors $^{(8)}$ also found that most elderly with ST (60\%) had the lowest Braden scores and hence higher risk for developing pressure ulcers. Although developed with other age groups, study subjects have similar characteristics to those patients with cancer cited at the beginning of this paragraph, especially some precarious conditions of global health, especially 
the activity and mobility and therefore, they were also at higher risk for developing pressure ulcers ${ }^{(8)}$.

There is still a lot to be done in order to elucidate the epidemiology of ST. The methodological diversity of the studies, as data collection and statistical processing of data and the different criteria used in the classification of ST, besides the multitude of scenarios and the target population, make it difficult and sometimes impossible to generalize the results. It was also highlighted the importance of the presentation of the quantitative results of prevalence studies with their respective confidence intervals, which statistically estimate how reliable the values found are ${ }^{(16)}$. Also, they recommend that such prevalence should be analyzed in subgroups such as gender and age, among other variables that may be considered relevant. Unfortunately, this recommendation was not performed in any of the eight studies analyzed.
Restriction of the publication language was one limitation of this study, resulting in the exclusion of a study, published in Chinese ${ }^{(25)}$.

Nevertheless, it is considered that the present study, through the summary of the knowledge about the prevalence of ST and factors associated with its occurrence, contributes to the development of protocols for prevention, and risk screening instruments for those wounds in the light of evidence-based practice.

\section{CONCLUSION}

The prevalence of ST ranged from $3.3 \%$ to $22 \%$ in hospital settings, and from $5.5 \%$ to $19.5 \%$, in homecare. It was mainly associated with advanced age and dependence on basic activities of daily life.

\section{RESUMO}

Objetivo: Identificar e analisar a prevalência de lesão por fricção e os fatores associados à sua ocorrência. Método: Revisão sistemática da literatura publicada até junho de 2014 com a inclusão de estudos publicados na íntegra em inglês, espanhol ou português. Os estudos foram analisados segundo o Strengthening the Reporting of Observational Studies in Epidemiology e o Guidelines for Critically Appraising Studies of Prevalence or Incidence of a Health Problem. Resultados: As análises de oito estudos mostraram prevalência de lesão de 3,3\% a $22 \%$ no cenário hospitalar e 5,5\% a 19,5\% no domiciliar.Idade avançada, dependência para as atividades básicas de vida diárias, idoso frágil, nível de mobilidade, comportamento agitado, arresponsividade, maior risco para o desenvolvimento concomitante de úlcera por pressão, comprometimento cognitivo, espasticidade e fotoenvelhecimento foram os fatores de risco citados. Conclusão: A prevalência de lesão variou de $3,3 \%$ a $22 \%$, estando associada principalmente à idade avançada e dependência para as atividades básicas de vida diárias.

\section{DESCRITORES}

Ferimentos e Lesões; Prevalência; Estudos Transversais; Epidemiologia; Revisão.

\section{RESUMEN}

Objetivo: Identificar y analizar la prevalencia de lesión por fricción y los factores asociados con su ocurrencia. Método: Revisión sistemática de la literatura publicada hasta junio de 2014 con la inclusión de estudios publicados integralmente en inglés, español o portugués. Los estudios fueron analizados según el Strengthening the Reporting of Observational Studies in Epidemiology y el Guidelines for Critically Appraising Studies of Prevalence or Incidence of a Health Problem. Resultados: Los análisis de ocho estudios mostraron prevalencia de lesión del 3,3\% al 22\% en el escenario hospitalario y del 5,5\% al 19,5\% en el domiciliario. Edad avanzada, dependencia para las actividades básicas de vida diarias, anciano frágil, nivel de movilidad, comportamiento agitado, falta de responsividad, mayor riesgo para el desarrollo concomitante de úlcera por presión, afectación cognitiva, espasticidad y fotoenvejecimiento fueron los factores de riesgo citados. Conclusión: La prevalencia de lesión varió del 3,3\% al 22\%, estando asociada principalmente con la edad avanzada y la dependencia para las actividades básicas de vida diarias.

\section{DESCRIPTORES}

Heridas y Traumatismos; Prevalencia; Estudios Transversales; Epidemiología; Revisión.

\section{REFERENCES}

1. Groom M, Shannon RJ, Chakravarthy D, Fleck CA. An evaluation of costs and effects of a nutrient-based skin care program as a component of prevention of skin tears in an extended convalescent center. J Wound Ostomy Continence Nurs. 2010;37(1):46-51.

2. Stephen-Haynes J, Callaghan $\mathrm{R}$, Bethell E, Greenwood M. The assessment and management of skin tear in care homes. Br J Nurs. 2011;20(11):S12-6.

3. LeBlanc K, Baranoski S. Skin tears: state of the science: consensus statements for the prevention, prediction, assessment, and treatment of skin tears. Adv Skin Wound Care. 2011;24(9):2-15.

4. Carville K, Lewin G, Newall N, Haslehurst P, Michael R, Santamaria N, et al. STAR: a consensus for skin tear classification. Primary Intention. 2007; 15(1):8-25.

5. Edwards H, Gaskill D, Nash R. Treating skin tears in nursing home residents: a pilot study comparing four types of dressings. Int J Nurs Prac. 1998;4(1):25-32

6. Strazzieri-Pulido KC, Santos VLCG, Carville K. Cultural adaptation content validity and inter-rater reliability of the "STAR Skin Tear Classification System". Rev Latino Am Enfermagem [Internet]. 2015 [cited 2015 Mar 22];23(1):155-61. Available from: http://www.scielo.br/ pdf/rlae/v23n1/0104-1169-rlae-23-01-00155.pdf

7. Meuleneire F. Using a soft silicone-coated net dressing to manage skin tears. J Wound Care. 2002;11(10):365-9. 
8. Payne RL, Martin ML. Defining and classifying skin tears: need for a common language. Ostomy Wound Manage. 1993;39(5):16-20.

9. Malone ML, Rozario N, Gavinski M, Goodwin J. The epidemiology of skin tears in the institutionalized elderly. J Am Geriatri Soc. 1991:39(6):591-5.

10. Battersby L. Exploring best practice in the management of skin tears in older people. Nurs Times. 2009;105(16):22-6.

11. White M, Karam S, Cowell B. Skin tears in frail elders: a practical approach to prevention. Geriatric Nurs. 1994;15(2):95-9.

12. Lopez V, Dunk AM, Cubit K, Parke J, Larkin D, Trudinger M, et al. Skin tear prevention and management among patients in the acute aged care and rehabilitation units in the Australian Capital Territory: a best practice implementation project. Int J Evid Based Healthc. 2011;9(4):429-34.

13. Bank D, Nix D. Preventing skin tears in a nursing and rehabilitation center: an interdisciplinary effort. Ostomy Wound Manage. 2006:52(9):38-46.

14. Higgins JPT, Green S, editors. Cochrane handbook for systematic reviews of interventions. Version 5.1.0 updated March 2011 [Internet]. London: Cochrane Collaboration; 2011 [cited 2014. Available from: www.cochrane-handbook.org

15. Malta M, Cardoso LO, Bastos FI, Magnanini MMF, Silva CMFP. STROBE initiative: guidelines on reporting observational studies. Rev Saúde Pública. 2010;44(3):559-65.

16. Loney PL, Chambers LW, Bennett KJ, Roberts JG, Stratford PW. Critical appraisal of the health research literature: prevalence or incidence of a health problem. Chronic Dis Can. 1998;19(4):170-6.

17. Carville K, Lewin G. Caring in the community: a wound prevalence survey. Primary Intention. 1998;6(2):54-62.

18. Carville K, Smith JA. A report on the effectiveness of comprehensive wound assessment and documentation in the community. Primary Intention. 2004;12(1):41-8.

19. McErlean B, Sandison S, Muir D, Hutchinson B, Humphreys W. Skin tear prevalence and management at one hospital. Primary Intention. 2004;12(2):83-6,8.

20. McLane KM, Bookout K, McCord S, McCain J, Jefferson LS. The 2003 national pediatric pressure ulcer and skin breakdown prevalence survey: a multisite study. J Wound Ostomy Continence Nurs. 2004;31(4):168-78.

21. Santamaria N, Carville K, Prentice J. Woundswest: identifying the prevalence of wounds within western Australia's public health system. EWMA J. 2009;9(3):13-8.

22. Amaral AFS, Strazzieri-Pulido KC, Santos VLCG. Prevalence of skin tears among hospitalized pacients with cancer. Rev Esc Enferm USP [Internet[. 2012 [cited 2014 Aug 22];46(n.spe):44-50. Available from: http://www.scielo.br/pdf/reeusp/v46nspe/en_07.pdf

23. LeBlanc K, Christensen D, Cook J, Culhane B, Gutierrez O. Prevalence of skin tears in a long-term care facility. Wound Ostomy Continence Nurs. 2013;40(6):580-4.

24. Koyano Y, Nakagami G, lizaka S, Minematsu T, Noguchi H, Tamai N, et al. Exploring the prevalence of skin tears and skin properties related to skin tears in elderly patients at a long-term medical facility in Japan. Int Wound J. 2014 Mar 28. [Epub ahead of print]

25. Hsu M, Chang S. A study on skin tear prevalence and related risk factors among inpatients. Tzu Chi Nurs J. 2010;9(4):84-95.

26. Bateman S. Treating skin tears with a new antimicrobial foam dressing. Wounds UK. 2012;8(1):95-9.

27. Naylor EC, Watson RE, Sherratt MJ. Molecular aspects of skin ageing. Maturitas. 2011;69(3):249-56.

28. Battie C, Jitsukawa S, Bernerd F, Del Bino S, Marionnet C, Verschoore M. New insights in photoaging, UVA induced damage and skin types. Exp Dermatol. 2014;23 Suppl 1:7-12.

29. Irving V, Bethell E, Burtin F. Neonatal wound care: minimizing trauma and pain. Wounds. 2006;2(1):33-41.

30. Santos VLCG. SCALE: modificações da pele no final da vida [tradução]. Rev Estima. 2009;7(3):42-4. 